Studies in African Linguistics

Volume 20, Number 1, April 1989

\title{
THEMATIC LINKING IN HAUSA ASYMMETRIC COORDINATION*
}

\author{
Linda Schwartz \\ Indiana University
}

\begin{abstract}
This paper investigates "asymmetric coordination" in Nigerian Hausa. A range of constructions is presented in which asymmetric coordination occurs, and their syntactic and semantic properties are established. A "regularizing" analysis is considered, in which asymmetric coordination is represented as a symmetric coordination headed by an empty category, but this is rejected due to the exceptional distributional properties which would have to be assumed for the construction. An interpretive analysis is proposed which has the effect of incorporating the feature information of an independent NP marked by a "linker" into a dependent plural argument, and symmetric and asymmetric coordination are distinguished as involving interpretive operations of set union and set unification, respectively.
\end{abstract}

\section{Introduction}

The work reported on in this paper is part of a larger investigation I have undertaken concerning the typological properties of what I'll call "asymmetric co-

\footnotetext{
* The research presented in this paper was supported by an Indiana University grant-in-aid 19871988 and an Indiana University Summer Faculty Fellowship 1988. Portions of the content of this paper were presented as "A unified analysis of asymmetrical coordination in Hausa" at the Thirteenth Annual Minnesota Conference on Language and Linguistics, Minneapolis, October 1987 and as "Thematic linking in Hausa" at the Nineteenth Annual African Linguistics Conference, Boston, April 1988. I am very grateful to Dr. Ismail Junaidu and Dr. Sammani Sani for the data, grammaticality judgements, and meaning judgements which they have provided for me as well as their help in understanding the structure of Hausa, to Abdoulaye Idi for clarifying some structural and semantic judgements for me, to Paul Newman for his careful and patient reading of drafts of this paper and its predecessors and his help in understanding the structure of Hausa, to Russell Schuh for his insightful comments on a draft of this paper, and to Kemp Williams and Frank Wright for discussing various aspects of Hausa structure with me; I am responsible for all interpretations and analysis of the data.
} 
ordination"; other studies on aspects of these constructions appear in Schwartz [1987a, 1987b, 1988a, 1988b, 1989, in preparation]. In this paper, I'll use the term "thematic coordination" to refer to an interpretation in which two (or more) participants share the same thematic role within a clause. In many languages, the symmetry of thematic coordination is expressed in a symmetric syntax of the English coordination type shown in (1).
(1) a. Sam and Sally went to the movie
b. They saw Sam and Sally
c. We sent letters to Sam and Sally

However, in many other languages, thematic coordination can be expressed in an asymmetric syntax, generally with overtones of greater cohesion along one of a number of parameters (see Schwartz [1987b]). In previous work, I have referred to the syntax of structures of this type as "asymmetric coordinations". In Hausa, there is a particularly rich range of asymmetric syntactic structures of this type, as shown in (2-4), with the crucial parts of the structure given in bold face type. ${ }^{1}$

(2) mun je kasuwa da Audu

1 PL go market \& Audu

'Audu and I went to the market'
(3) Audu ya: gan mu jiya da Binta Audu $3 \mathrm{~m}$ see $1 \mathrm{PL}$ yesterday \& Binta
'Audu saw Binta and me yesterday'

(4)
a. Audu ya: fada mand
labari da Binta
Audu $3 \mathrm{~m}$ tell IOM+1PL story \& Binta
'Audu told the story to Binta and me'

b. *Audu ya: fada mana da Binta labari

\footnotetext{
${ }^{1}$ The crucial judgements and interpretations of the structures involved are from Nigerian Hausa: Dr. Junaidu is from Katsina and Dr. Sani is from Kano. I am informed by Attouman Bachir that some of the grammaticality judgements and interpretations represented here do not hold for the Hausa spoken in Niger. Hausa examples are cited for the most part using standard Hausa orthography. However, this orthography does not represent tone and vowel length. Since tone and vowel length are distinctive in pronominal forms and since it is crucial in this study to distinguish the various pronominal paradigms, these forms will be marked for tone and length. High tone will be unmarked, and low tone will be marked with a grave accent ( $($ ). A colon (:) will mark long vowels.
} 
In (2), the plural morphology on the obligatory pronominal element mun preceding the main verb is the only overt cue to a thematic coordination, and the NP linked to the clause by $d a$ is interpreted as one member of that coordination. In (3), the thematic coordination is manifested syntactically by a plural direct object pronoun mù and an NP linked by da. 2 The crucial dual interpretation of (3) indicates that the plural pronoun is not necessarily interpreted literally but, as in (2), can simply indicate that an argument, i.e. a participant playing a role in an event specified by the predicate, consists of a set, where the NP linked by da is one member of the set. In (4), the thematic coordination is manifested syntactically as a plural indirect object pronoun (identified by the marker $\mathrm{ma}$ ) and an NP linked by da. It is clear from examples (2)-(4) that the overt syntactic elements of the thematic coordination do not form a surface syntactic constituent. In (2), the da-phrase is separated from the preverbal pronominal element by the verb and its subcategorized complements. In (3), the da-phrase is separated from the direct object pronoun by a temporal adjunct, and in (4), the da-phrase is obligatorily separated from the indirect object pronoun by the direct object, as demonstrated by the ungrammaticality of $(4 b)$.

Sentences like those in (2)-(4) are glossed here with a dual interpretation, where the thematic coordination has only two members. Since Hausa has no dual vs. plural contrast, sentences like those in (2)-(4) can also be interpreted compositionally, as they would have to be in a language like English. That is, taking (2) for example, mun is plural, so it can be interpreted as identifying a set of two or more participants, and adding da NP yields a total of three or more. In fact, (2) can have all three of the interpretations given in (5).

(5) i. Audu and I went to the market.

ii. We and Audu went to the market.

iii. We went to the market with Audu. (dual asymmetric coord.)

(plural asymmetric coord.)

(plural comitative)

While the compositional interpretations are probably universally available for constructions of this type in human languages (unless they have a dual/plural distinction), only a subset of languages allow the non-compositional dual interpretation like that in $(5 \mathrm{i})$. In the discussion that follows, I will concentrate on that crucial dual interpretation.

\footnotetext{
2In Hausa, nouns are not case-marked. Pronouns are traditionally divided into several paradigms: the independent paradigm, the direct object paradigms, the indirect object paradigm, and various preverbal pronoun paradigms which vary with tense/aspect. The grammatical function terms subject, direct object, and indirect object as used in this paper will refer to NP's (either nounheaded or pronoun-headed) for which the corresponding pronoun is from the preverbal paradigms, the direct object paradigm or the indirect object paradigm respectively. Thematic role terms used here will include the term "dative" to refer to animate goals and benefactives.
} 
I argue in this paper that the da-phrase in such constructions behaves syntactically like an adjunct but semantically like part of one of the grammatical relations encoded pronominally on the preverbal pronoun, the verb, or the indirect object marker. I propose an analysis which has the effect of semantically combining the information of the da-phrase with the information of a plural pronominal argument within its clause, where the NP linked by da would then assume the thematic role of the pronominal argument and be interpreted as a member of the set specified by the pronominal argument.

In $\$ 2$, I briefly present the relevant facts and generalizations about the syntactic and semantic properties of asymmetric expressions of thematic coordination in Hausa. In $\S 3$, I give reasons why an empty category analysis of this construction is problematic. In $\$ 4$, I present an interpretive analysis along the lines outlined above. In $\$ 5$, I deal with some apparent problems for the analysis presented in $\$ 4$, and in $\S 6$, I propose a formal distinction between symmetric and asymmetric coordination.

\section{The Structure of Asymmetric Coordination in Hausa}

2.1. Symmetric coordinations, asymmetric coordinations, and comitatives. The first step is to distinguish asymmetric coordinations from symmetric coordinations and comitative structures.

2.1.1. Symmetric coordinations. Symmetric coordinations and comitatives are syntactically similar to asymmetric coordinations in Hausa, in that all involve the presence of the free morpheme da occurring before at least one NP. The following points are crucial in distinguishing symmetric coordination from asymmetric coordination:

i. Symmetric coordinations are optionally introduced by $d a$, and each subsequent conjunct is obligatorily preceded by $d a$, as shown in (6). ${ }^{3}$ There is no limit to the number of NP's which can be part of a symmetric coordination.
(6)

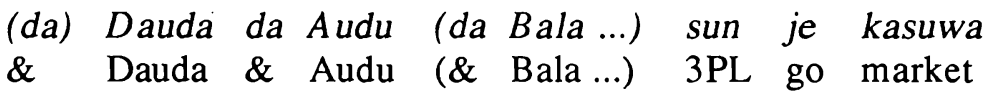
'Dauda and Audu (and Bala ...) went to the market'

\footnotetext{
${ }^{3}$ The morpheme $d a$ is not confined to these constructions. See $\$ 3$ for some further examples of da-phrases. For an extensive account of expressions using da as a linker, see Kraft [1970]. Da in its linking sense will be glossed " $\&$ " in examples.
} 
ii. When independent pronouns are conjoined in symmetric coordinations, there is no absolute person restriction on order within the coordination, as shown in (7). ${ }^{4}$
a. da ni: da shi: mun je kasuwa
'he and I went to the market'
\& $1 \& 3 \mathrm{~m} \quad 1 \mathrm{PL}$ go market

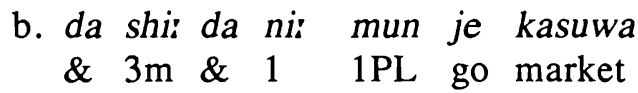

iii. In the case of indirect object symmetric coordinations, it is acceptable for all members of the coordination to appear before the direct object, as shown in (8) and (9).

(8) Audu ya: kawo wa da Bala da Binta abinci

Audu $3 \mathrm{~m}$ took DM \& Bala \& Binta food

'Audu took food to Bala and Binta'

(9) Audu ya: kawo wa da ni: da Binta abinci

Audu $3 \mathrm{~m}$ took DAT \& 1 \& Binta food

'Audu gave food to me and Binta'

More generally, symmetric coordinations must be contiguous. This is demonstrated by the ungrammaticality of (10) and (11), where subject and direct object respectively are discontinuous.
(10) *da Audu sun je Kano da Bala \& Audu 3PL go Kano \& Bala

(11) *Audu ya: kawo wa da Bala abinci da Binta Audu 3m bring DAT \& Bala food \& Binta

2.1.2. Asymmetric coordinations. Asymmetric coordinations differ from symmetric coordinations in the following points:

4There seems to be a $1<2<3$ preference for conjoined pronouns. This preference is apparently
less strong for a pronoun conjoined with a noun, so that in (7), (a) is preferred over (b), but in
( 7 '), there is no corresponding preference.

(7') a. da ni: da Audu mun je kasuwa \& 1 \& Audu 1PL go market

b. da Audu da ni: mun je kasuwa \& Audu \& 1 1PL go market

'Audu \& I went to the market' 
i. Asymmetric coordinations cannot occur where the plural pronoun is from the independent paradigm (glossed in the following examples as IND). This is illustrated in (12) for preverbal pronouns, parallel to (2) repeated here as (13). In (12), where there is an independent subject pronoun, there is no dual interpretation.

(12) mu: mun je kasuwa da Audu 'we and Audu went to the market' 1PL-IND 1PL go market \& Audu

(13) mun je kasuwa da Audu (=(2)) 'Audu and I went to the market'
1PL go market \& Audu

ii. This entails that the "coordinate" elements of asymmetric coordinations cannot be interchanged while still maintaining the crucial dual interpretation, as shown in (14), where in (14b), the plural pronominal element is after da and a third person singular pronominal element occurs preverbally.

(14)
a. mun je kasuwa da shi: 'he and I went to the market'
(dual)
$1 \mathrm{PL}$ go market \& $3 \mathrm{~m}$
b. ya: je kasuwa da mu:
$3 \mathrm{~m}$ go market \& $1 \mathrm{PL}$
'he went to the market with us' (non-dual)

The sentences in (15) demonstrate the same point for asymmetric coordination with object function.
(15)
a. sun gan mù da ita
3PL see $1 \mathrm{PL} \& 3 \mathrm{f}+\mathrm{IND}$
'they saw me and her'
(dual)
b. sun gan tà da mu:
3PL see 3f \& 1PL+IND
'they saw her and us' (non-dual)

In (15a), the first person plural pronoun mù is from the direct object paradigms, and the third person feminine singular pronoun ita is from the independent paradigm. Here, the crucial dual interpretation is possible. In (15b), the third person feminine singular pronoun tà is from the direct object paradigms, and the first person plural pronoun mu: is from the independent paradigm. Here, the dual interpretation is not possible.

iii. From $\mathbf{i}$ it also follows that in asymmetric coordination, where no independent pronoun is present, the "linking morpheme" $d a$ cannot occur before each constituent of the thematic coordination, as shown in (16-18). This is because, as 
stated earlier, da takes as its object only pronouns from the independent paradigm. I will demonstrate in $\$ 4$ that none of the plural pronouns crucial to the dual interpretation in asymmetric coordinations are syntactically independent.

(16) *da mun je kasuwa da Audu 'Audu and I went to the market' \& 1PL go market \& Audu

(17) Audu ya: gan *da mù jiya da Binta Audu $3 \mathrm{~m}$ see \& $1 \mathrm{PL}$ yesterday \& Binta 'Audu saw Binta and me yesterday'

(18) Audu ya: fada *da manà labari da Binta Audu $3 \mathrm{~m}$ tell \& DAT $+1 \mathrm{PL}$ story \& Binta 'Audu told the story to Binta and me'

iv. Asymmetric coordinations are obligatorily discontinuous for NPs with dative thematic function when a theme-object is present, as shown in (4b). ${ }^{5}$ Examples (19) and (20) illustrate this further.

(19) a. Bala ya: kawo manà abinci da Musa

Bala 3m bring DAT-1PL food \& Musa

'Bala brought food to me and Musa'

b. *Bala ya: kawo manà da Musa abinci

(20) a. an biya mù albashinmu da Musa

3impers pay 1 PL salary+1POSS \& Musa

'the salary was paid to me and Musa' (lit.: 'one payed the salary ...')

b. *an biya mù da Musa albashinmu

In (19), the verb kawo 'bring' has two NP objects. The one with dative thematic function occurs immediately following the verb and is marked with an indirect object marker ( $w a$ for NP, ma for pronouns in Standard Kano Hausa). In (20), the verb biya 'pay' is one of a very few verbs in Hausa which take two NP objects where the object with dative thematic function occurs immediately following the verb and is taken from the direct object paradigms. In examples of both types, the NP with

5This obligatory discontinuity can be considered to be a result of the dependent nature of the object pronouns which immediately follow the verb in Hausa. See $\$ 4$ for additional discussion of this point. 
dative thematic function precedes the NP with theme function and in both cases, asymmetric coordination is necessarily discontinuous.

v. Asymmetric coordination is binary-da can only introduce one NP, as shown in (21) -cf. (6).

\section{(21) mun je kasuwa da Bala *da Audu 1PL+PAST go market \& Bala \& Audu}

2.1.3. Comitatives. The structure in (2) can be the expression of an asymmetric coordination, where there is no independent subject noun phrase or pronoun and where the da-phrase is interpreted as one member of the set specified by the plural preverbal pronoun. Recall that the crucial interpretation is one where the set has only two members-that is, a dual interpretation, as given in (5i). Comitative structures overlap to a great extent with asymmetric coordinations, as shown by the interpretation in (5iii). However, they differ from the asymmetric coordination structure in several ways. First, they allow a singular preverbal pronoun, as in (22), or singular object pronoun, as in (23).

(22) (ni:) na: je kasuwa da Audu

$1+$ IND 1 go market \& Audu

'I went to the market with Audu'

(23) Audu ya: gan ni da Binta

Audu $3 \mathrm{~m}$ see 1 \& Binta

'Audu saw me (when I was) with Binta'

Second, comitative constructions are compatible with the presence of pronouns from the independent paradigm, as shown by the permissibility of the independent subject pronoun in (22) and by the plural comitative interpretation of (2) given in (5iii). Lastly, comitatives differ from coordinations in the control of adjunct modifiers, as will be shown in $\$ 2.3$.

It is important to distinguish the comitative and coordinate structures and their corresponding interpretations, since these apparently have distinct entailments in at least some contexts. This is not so obvious for the examples given above, since many involve a motion verb, and "accompaniment" as well as thematic coordination would both require that the referent of the da-marked NP follow the same trajectory as that of the subject along the path specified by the motion verb. However, with non-motion verbs, the distinct entailments become clearer, as seen in examples (24) and (25). 
(24) sun mutu tare da abokinsa

3PL die together \& friend-3/POSS

i) 'he and his friend died'

ii) 'they died, and his (somebody else's) friend was with them and may or may not have died'

(25) Audu ya: mutu tare da abokinsa

Audu $3 \mathrm{~m}$ die together \& friend-3/POSS

'Audu died with his friend (who may or may not have died too)'

The asymmetric coordination interpretation (24i) of a sentence like (24) entails that everyone died, while the comitative interpretation (24ii) does not have this entailment. This is also shown in (25), which is only comitative because of the singular possessive pronoun. Note also in the interpretation (24i) that with the dual reading, the third singular possessive on aboki 'friend' can be coreferential with the other member of the thematic coordination, but it cannot be in (24ii). This is because in the latter interpretation, the subject is plural while the possessive is singular. While it is the case that the comitative construction may have the interpretation that everyone died, the point is that this is not a necessary interpretation, and the plausibility of the interpretation varies with the pragmatics of the situation. 6

In this section, I have distinguished three very similar constructions: symmetric coordination, asymmetric coordination, and comitative. Only asymmetric coordination will have plural morphology but a permissible dual interpretation. In the rest of the paper, I will take the permissible occurrence of da before each conjunct as diagnostic of symmetric coordination and the permissible absence of a plural pronoun as diagnostic of a comitative.

2.2. Extraction structures. Evidence from extraction structures indicates that asymmetric coordinations apparently do not behave like syntactic coordinate

6There is actually more slippage here than I can account for easily, even though some cases, such as that in (24-25), seem quite clear. In a sentence that is pragmatically loaded against the participation of the $d a$-marked NP, such as (i) and (ii), the comitative and asymmetric coordination interpretations are much closer: in this case, even with the crucial dual interpretation of (ii), first person and baby, speakers feel that this does not entail that the baby must be working:

(i) ta: yi aiki a gona da jariri $3 f$ do work in field \& baby

'she worked in the fields with the baby'

(ii) mun yi aiki a gona da jariri

$1 P L$ do work in field \& baby

'I worked in the fields with the baby' 
structures of the English type, in that the sequence [da NP] can be displaced from its postverbal position in topic constructions and focus constructions ${ }^{7}$ and still maintain the crucial dual interpretation, as shown in the examples (26-30). 8

Topic

(26) da Bala (kam), mun je kasuwa

\& Bala TOP 1PL go market

'as for Bala, he and I went to the market'

(27) da Musa (kam), Audu ya: gan mù

\& Musa TOP Audu 3m see 1PL

'as for Musa, Audu saw me and him'

Focus

(28) da Bala (ne) muka jei kasuwa

\& Bala FOC 1PL+rc 9 go market

'BALA and I went to the market'

(29) da Musa (ne) Audu ya gan mù

$\&$ Musa FOC Audu 3m+rc see 1PL

'Audu saw me and MUSA'

${ }^{7}$ See Junaidu [1987] for an analysis of topic and focus constructions in Hausa. Both of my primary consultants allowed forms with overt topic morphology and without resumptive pronouns, as these examples illustrate. It should be noted, however, that topic structures also occur with resumptive pronouns. These would not be analyzed as extraction structures, however, and would not be relevant to the issue addressed here. If there are speakers with more restrictive topic structures which require resumptive pronouns, however, the same point can be made taking the evidence from the focus structures.

${ }^{8}$ This evidence would also indicate that what I am calling symmetric coordination in Hausa is not totally analogous to English coordination, since extraction is allowed there as well, as shown in (i) and (ii) below.

(i) da Binta ce, da Audu sun tafi
\& Binta TOP \& Audu 3PL go

'as for Binta, she and Audu went'

(ii) da Musa ne da Audu za: sù zo

\& Musa FOC \& Audu FUT 3PL come

'MUSA and Audu will come'

${ }^{9}$ The abbreviation $r c$ is used here for the "relative completive" aspect in Hausa. 

(30)
$\begin{array}{llllll}\text { da } & \text { Binta } & \text { (ne) ya fada manà labari } \\ \text { \& } & \text { Binta } & \text { TOP } & 3 \mathrm{~m}+\mathrm{rc} & \text { tell } & \mathrm{DAT}+1 \mathrm{PL} \\ \text { story }\end{array}$
'he told me and BINTA the story'

(31) da wa Lami ta ba kù abinci?

$\&$ who Lami $3 f+r c$ give $2 P L$ food

'who (sg.) besides you (sg.) did Lami give food to?'

(lit.: 'and who did Lami give you food?')

The dual interpretation is also possible in relative clauses as shown in (32). However, as can be seen from these examples, Hausa relative clauses are formed using a resumptive pronoun strategy, so these are not extraction structures. 10

\section{Relative Clause}

(32) matar da ya gan mu da ita tana: zuwa Kano woman REL $3 \mathrm{~m}+\mathrm{rc}$ see $1 \mathrm{PL} \&$ her $3 \mathrm{f}+\mathrm{PROG}$ come Kano 'the woman that he saw me and her is coming to Kano'

2.3. Control. Even though there seems to be no syntactic evidence that asymmetric coordinations behave like a syntactic coordination, control evidence indicates that they do behave like a single grammatical relation, in that the da-phrase is interpreted as part of the set which can function as controller in obligatory control structures. For example, asymmetric coordinations can antecede reciprocal pronouns, as shown in (34), and function as controllers for adjunct modifiers, as shown in (36).

(33)

da Audu da Dauda suna: dukan juna

\& Audu \& Dauda 3PL+prg beat RECIP

'Audu and Dauda are beating each other'

10WH-questions may also have a form in which the WH-phrase is not extracted, in which case the syntactic structure and the possibility of dual interpretation is identical to that of a declarative sentence, as illustrated below.

(32') Lami ta: ba ku abinci da wa:?

Lami 3f give 2PL food \& who

'Lami gave food to you and whom?'

(This sentence can be appropriate if the Questioner knows that only one other person besides the Addressee got the food.) 


\section{(34) suna: dukan juna da Audu}

3PL-prg beat RECIP \& Audu

'he and Audu are beating each other'

In (33) is a symmetric coordination, da Audu da Dauda, which antecedes the reciprocal pronoun juna. In (34), the discontinuous asymmetric coordination suna:..da Audu likewise can antecede juna. Da-phrases in asymmetric coordinate structures can also function as part of the set which is a controller for adjunct modification, as shown in (36). Example (35) shows that the subject functions as controller of an adjunct modifier such as agajiye 'tired'. Example (36) shows that the da-phrase of asymmetric coordination functions as part of the set of participants specified by the subject (as manifested by the preverbal plural pronoun).

(35) Audu ya: isa kasuwa a gajiye

Audu 3PL arrive market at tiredness

'Audu arrived at the market tired'

(36) a. mun isa kasuwa a gajiye da Audu

$1 \mathrm{PL}$ arrive market at tiredness \& Audu

b. mun isa kasuwa da Audu a gajiye

1PL arrive market \& Audu at tiredness

'Audu and I arrived at the market tired'

Example (36) also supports the adjunct analysis of the da-phrase in that the position of the da-phrase is free relative to the adjunct modifier, while postverbal adjunct modifiers generally follow objects, just as asymmetrically coordinate indirect objects follow direct objects as in (4). As noted in Section 2.1.3, adjunct modification distinguishs asymmetric coordinations from comitatives, in that in comitatives, the da-phrase is not included in the controller, as shown in (37),

\section{(37) na: isa kasuwa da Audu a gajiye \\ 1 arrived market \& Audu at tiredness \\ 'I arrived at the market tired (and) with Audu'}

while (36) shows that the da-phrase is included in the controller for asymmetric coordinations. In summary, asymmetric coordinations in Hausa do not seem to behave like constituents but do seem to have the status of unitary grammatical relations. 


\section{An Empty Category Analysis}

In this section, I argue that the da-phrase of asymmetric coordinations does not have the distribution or behavior of a noun phrase in Hausa but rather has the distribution and behavior of an adjunct phrase. On this basis, I conclude that an empty category analysis is not appropriate for these structures.

It might seem to be initially plausible to unify the analysis of symmetric and asymmetric coordinate structures in Hausa by assuming that the structure of the overt sequence [da NP] in asymmetric coordination is actually a symmetric coordination with the da-phrase conjoined to an empty category, as proposed for a similar but not identical structure in Irish by McCloskey and Hale [1984] and McCloskey [1986]. This "regularizes" asymmetric coordination by making it a subtype of symmetric coordination. This hypothetical structure is shown in (38).

$$
\text { ... [NP e da NP] ... }
$$

Under an EC analysis, it would be this symmetric coordinate structure which would control the subject agreement of the preverbal pronoun or stand in apposition to the plural direct or indirect object pronoun. This analysis would be supported by the fact that symmetric coordination in Hausa uses the same linking morpheme da and by the assumption that Hausa is a pro-drop language, as argued in Tuller [1986]. This solution poses problems, however.

First, the distribution of the empty category in these constructions would not be the same as the distribution of other hypothesized empty categories in Hausa. It is true that Hausa finite clauses do not require independent nominal subjects, as shown in (39), where the pro-drop structure can still have a definite interpretation (typical of pro-drop languages). However, omission of objects is much more restricted, while no corresponding restrictions apply to object asymmetric coordination. Thus, only definite inanimate direct objects may be omitted, as shown in (40), while definite objects with dative thematic function cannot be omitted at all, as shown in (41) and (42).

a. Audu ya: ga Bala

Audu 3m see Bala

'Audu saw Bala'

b. ya: ga Bala

$3 \mathrm{~m}$ see Bala

'he saw Bala' 
(40) Audu ya: gani

Audu $3 \mathrm{~m}$ see[-OBJ] ${ }^{11}$

'Audu saw it/*him'

(41) Audu ya: kawo abinci

Audu 3M+PAST bring food

'Audu brought food (to somebody/*to them)'

(42) Audu yai ba da abincil2

Audu 3M+PAST gave \& food

'Audu gave food (to somebody/*to them)'

On the other hand, asymmetric coordinate structures occur freely with direct object function only with an animate interpretation (preferably a human interpretation), as in (43),

(43) Audu yai gan sù da Binta

Audu $3 \mathrm{~m}$ see $3 \mathrm{PL} \&$ Binta

'Audu saw them/*those things and Binta'

and they occur freely with objects of dative thematic function as shown in previous examples such as (19) and (20).

It might be argued that subject-linked da-phrases occur postverbally because of the correlation claimed in Rizzi [1982] between pro-drop and postverbal subject position, but Tuller [1986] observes that overt subjects in Hausa cannot appear postverbally, as shown in (44). 13
a. *ya:
je Audu kasuwa
3m-PAST go Audu market
b. *ya:
je kasuwa Audu
3m-PAST go market Audu

\footnotetext{
${ }^{11}$ The verb gani 'see' is one which varies in form depending on the presence or absence of an overt postverbal direct object as well as on whether that object is pronominal or not. The form given here is the one used when no overt postverbal object is present.

12In (42), da appears before the theme abinci 'food' because ba da 'give away' is the short form of bayar da, a grade 5 verb. See Newman [1983] for a discussion of the syntax and semantics of grade 5 verbs.

${ }^{13}$ There is an "afterthought" construction in which subjects may appear at the end of a clause, but this is intonationally and functionally different from postverbal subjects in pro-drop languages.
} 
A further distributional problem for an EC analysis occurs in the case of objects, in that nominal and pronominal objects with the same grammatical function are elsewhere in complementary distribution, and they may not cooccur in a single clause, as shown in (45) and (46). Example (45) shows that the nominal and pronominal objects cannot cooccur in the order nominal $>$ pronominal (this is true regardless of whether the pronominal object appears in direct object form or independent form), and (46) shows that they likewise cannot occur in the reverse order. 14

\section{(45) ta: ga Dauda (*shi/*shi:) \\ 3f see Dauda (3m-obj/3m-IND) \\ 'she saw Dauda'}

(46) ta: gan shi (*Dauda)
3f see him (*Dauda)
'she saw him'

Under the EC analysis, it would have to be stipulated that objects may be "doubled" only in the case of asymmetric coordinations. 15 That is, a special provision would have to be made such that only if the nominal object contains a coordination with an $\mathrm{EC}$, it may cooccur with the pronominal object, as in (47).

\section{(47) ta: gan mu da Dauda \\ 3f-PAST see 1PL \& Dauda \\ 'she saw me and Dauda'}

A last point regarding the lack of NP behavior for the da-phrase is that if the daphrase is given the analysis in (38), we might expect extraction to be impossible (a Subjacency violation, in which a conjunct is moved outside both its NP and its clause), but as seen in (26-30), extraction is possible. However, although this behavior is interesting and calls for further investigation, it does not distinguish symmetric from asymmetric coordination in Hausa and thus cannot be taken to argue specifically against the EC analysis of asymmetrical coordination, but rather calls into question the structure of coordination in general in Hausa.

The position which the da-phrases of asymmetric coordination occupy, after the verb and its subcategorized nominal objects, is the typical position of adjunct

${ }^{14}$ In (45), the verb form ga indicates that the following object is nonpronominal, and in (46), the verb form gan indicates that the following object is pronominal.

${ }^{15}$ Again, it is possible to have a nominal in apposition to the pronominal object in clause-final position, as in (46), but this is usually understood to be emphatic and to support an intonation break, while a sentence with asymmetric coordination does not have such a break. 
phrases in Hausa, including da-phrases with other functions. A sample of such phrases is given in (48-50). Example (51) shows that this is also the typical position of a locative adjunct. (See Kraft [1970] for a detailed examination of the various uses of da.)

(48) yai soke shi da wuka

$3 \mathrm{~m}$ stab $3 \mathrm{~m}$ da knife

'he stabbed him with a knife'

(49) Audu ya: je gonarsa da safe

Audu 3m go farm-his da morning

'Audu went to his farm in the morning'

(50) ya: koma gida da fushi

$3 \mathrm{~m}$ return home da anger

'he returned home angrily'

(51) ya: sa tasa a kan tebur

$3 \mathrm{~m}$ put dish on top table

'he put the dish on the table'

In sum, the distributional evidence presented here causes problems for an EC analysis of asymmetric coordination in Hausa in two ways: first, such an analysis entails that the da-phrase of asymmetric coordination would have the distribution of an NP of the corresponding grammatical relation, but it does not; and second, such an analysis would not be able to account for the adjunct-like distribution which it does have.

There are other ways in which a regularized symmetric coordinate structure could be assumed for asymmetric coordination if multistratal syntactic analyses are considered. One of these involves a Relational Grammar-type raising analysis where plural pronoun information is registered on a dependent pronominal element even though a symmetric coordination present in one stratum is broken up by raising one conjunct (perhaps an EC or a pronoun subject to deletion) out of the coordination to take over the grammatical relation of the whole coordination in the next stratum, leaving the da-phrase as the "remainder". This would account for the requirement that a plural dependent pronoun must be present (the result of plural agreement with the symmetric coordination) and for the adjunct-like behavior of the da-phrase (which after raising has no grammatical relation status). Such an analysis has been proposed in Aissen [1988] for Tzotzil, which has structures similar but not identical to asymmetric coordinate structures in Hausa. Another alternative would be to use a Government-Binding-type movement analysis, 
moving the da-phrase out of a grammatical relation position (to account for its adjunct position) while leaving a trace (to account for its theta-role assignment). It is not my intention in this paper to pursue a comparison between these multistratal alternatives and the monostratal one proposed in \$3. (However, I argue in Schwartz [1987a] that Aissen's raising analysis is problematic for the analysis of structures in Chilean Spanish which are similar to Hausa asymmetric coordination.)

\section{An Interpretive Analysis}

The analysis to be presented here is a monostratal analysis in which the structure of the sequence [da NP] will be assumed to be that of a da-phrase, i.e. this sequence is just like any other da-phrase, accounting for its syntactic distribution. To account for the dual interpretation, this phrase will then be "thematically absorbed" by a plural pronoun, where this pronoun can be manifested as either an object pronoun in the case of sentences like (3) and (4) or as the subject marking on the pronominal element of the tense/aspect complex in the case of sentences like (2). The pronouns in these positions will be taken to be dependent arguments, and it is these which will bear grammatical relations in the clause and receive thematic roles from the verb. "Dependent argument", as used here, refers to an element with pronominal features which is not syntactically independent and which has argument status.

\subsection{Evidence that the plural pronouns of asymmetric coordinations} are dependent. I will first establish that the pronominal elements to which the da-phrase is linked in the thematic coordination interpetation are not syntactically independent. 16 Evidence for this comes from the non-separability of the pronominal element and its "host".

The pronominal elements which cross-reference subject nominals occur in preverbal position and are closely fused with aspect markers. Aspect is distinguished by vowel length and tone as well as separate clitics in some cases. A sample of these pronominal elements is given in (52) for first person forms.

\section{Preverbal (subject) pronouns}

1

$1 \mathrm{PL}$

Completive

ná: $\quad$ mùn

Subjunctive

in mù

Continuative

ínà:

múnà:

Future I

zân

zá: mù

Future II

nâ:

mâ:

${ }^{16}$ Evidence of phonological dependence is not presented here. Such evidence is found in Newman [1979], where it is further claimed that the low tone direct object paradigm is more bound to the verb than the high tone paradigm, based on tonal evidence. 
Relative Completive

Relative Continuative

Habitual
ná
múkà
nákè:
múkè:
nákàn

There is no other morpheme which can intervene between the pronominal element and the aspect marker, even in those cases where these are separable phonologically, as in the relative continuative or habitual aspects. Tuller [1986] analyzes these preverbal elements consisting of pronominal and aspect features as INFL. In what follows, I will follow Sani [1987] and Tuller [1986] in assuming that the INFL plus VP form a syntactic unit which I will assume is I'.

One piece of evidence that object pronouns are dependent comes from the "modal particles". These words can apparently occur just about anywhere in a clause except word-internally. For example, they can separate the verb from its nominal direct object even though other constituents cannot, as shown in (53). However, they cannot separate the verb from its dependent pronominal direct object, as shown in (54).

(53) yai harbi dai Binta

'indeed, he shot Binta'

3m shot PRT Binta
a. yai harbi (*dai) ta
'indeed, he shot her'
$3 \mathrm{~m}$ shot (PRT) $3 \mathrm{f}$
b. yai harbi dai ita
3m shot PRT 3f-IND
idem

Although it is possible to express the meaning of a sentence like (54) by using the independent pronoun rather than the direct object form, as shown in (54b), the point is that the object form of the pronoun cannot be separated from the verb by any other morpheme. The non-occurrence of the modal particles between verb and object pronoun supports an analysis in which the direct object form of the pronoun is syntactically dependent on the verb.

Another piece of evidence that pronominal direct objects are more closely bound to the verb than nominal objects, brought to my attention by Paul Newman, has to do with the placement of the discontinuous negation marker ba...ba. In sentential negation in Standard Hausa, the first negative element appears before the preverbal pronoun and the last appears at the end of the clause. However, many speakers also allow the second negative element to appear earlier in the verb phrase. If the pronominal direct object were bound to the verb but the nominal direct object were not, we might expect that the second negative element çould appear between the verb and its nominal direct object, as shown in (55), but that it would appear only 
after the verb and its pronominal direct object, as shown in (56). This is exactly what occurs.
(55) ba
$\begin{array}{lll}\text { bai } & \text { kama ba doki } \\ \text { NEG+3m } & \text { catch } & \text { NEG horse }\end{array}$
'he didn't catch the horse'

(56)
a. bai
kama shi ba
'he didn't catch it'
$\mathrm{NEG}+3 \mathrm{~m}$ catch $3 \mathrm{~m}$ NEG
b. *bai kama ba shi

As noted earlier, indirect objects immediately follow the verb and are preceded by a marker ma for pronouns and wa for nouns. ${ }^{17}$ The pronominal forms used for indirect object are the same as the bound possessive pronouns except for the first person singular and plural forms. They are written as a single word with ma and are inseparable from it, unlike the nominal indirect objects, which may appear in topic position with wa occurring postverbally, as shown in (57-62). Example (58) shows that wa cannot be separated from the verb but its nominal object can, as shown in (59). 18 The parallel examples with pronominal indirect objects in (61) and (62) show that neither ma nor its pronominal object can appear separated from the verb.

(57) Audu ya: kawo wa Dauda abinci

Audu 3m bring IOM Dauda food

'Audu brought food to Dauda'

(58) *wa Dauda ne Audu ya kawo abinci
IOM Dauda FOC Audu $3 \mathrm{~m}+\mathrm{rc}$ bring food

(59) Dauda ne Audu ya kawo wa abinci

Dauda FOC Audu $3 \mathrm{~m}+\mathrm{rc}$ bring IOM food

'it was Dauda that Audu brought food to'

${ }^{17}$ These different forms most likely reflect distinct historical origins of these markers. See Newman [1982] for one interpretation of their origins.

18Paul Newman has pointed out to me that in the Guddiri dialect, wà $+N$ appears to the right of the direct object, i.e. is separable from the verb, while ma + pronoun appears immediately after the verb as in Standard Hausa. This further supports the dependent analysis of the object pronouns in this dialect. 
(60) Bala ya: fada masa labari

Bala $3 \mathrm{~m}$ tell $\mathrm{IOM}+3 \mathrm{~m}$ story

'Bala told him the story'

$\begin{array}{clll}\text { (61) } & \text { masa } & \text { ne } & \text { Bala ya fada labari } \\ \mathrm{IOM}+3 \mathrm{~m} & \text { FOC } & \text { Bala } 3 \mathrm{~m}+\mathrm{rc} & \text { tell news }\end{array}$

(62) *sa ne Bala ya fada ma labari

$3(\mathrm{IOM})$

There is another form of (62) which is grammatical. In this form, the independent pronoun is used in place of the bound direct object pronoun, and the pronominal indirect object marker is replaced with the nominal direct object marker, as shown in (63).

(63)

shi ne Bala ya fada wa labari
3m-IND FOC Bala $3 \mathrm{~m}+\mathrm{rc}$ tell DAT story
'it was him that Bala told the story to'

However, there is no corresponding non-focussed version of this sentence with the nominal indirect object marker and the free pronoun, as shown by the ungrammaticality of (64).

(64) *Bala ya: fada wa shi: labari

Bala 3m tell DAT 3m-IND story

Whatever the analysis of structures like (63) may be, there are no grammatical structures in which the pronominal indirect object marker is separated from the verb and none in which the pronominal indirect object is separated from its indirect object marker.

Tuller [1984] also shows that the nominal indirect object but not the pronominal indirect object can be separated from the verb and indirect object marker by a modal particle, as shown in (65-66), adapted from Tuller [1984:449].

(65) bai fada wa fa matarsa ba

NEG+3m+PAST speak IOM PRT woman+3POSS NEG

'indeed, he didn't speak to his wife'

(66) bai fada ma *fa ta ba

$\mathrm{NEG}+3 \mathrm{~m}$ speak DAT PRT $3 \mathrm{f}$ NEG

'indeed, he didn't speak to her' 
(67) bai fada *fa mata ba

$\mathrm{NEG}+3 \mathrm{~m}$ speak PRT DAT-3f NEG

'indeed, he didn't speak to her'

It remains to be demonstrated that pronoun forms from the independent paradigm are separable from tense/aspect, verb and indirect object marker. This evidence is given in (68-72), using evidence from extraction structures and modal particles. 19

(68) ita ce ta je kasuwa

$3 f+I N D$ FOC $3 f+r c$ go market

'it was she who went to the market'

(69) ita fa ta: je kasuwa

3f+IND PRT 3f go market

'indeed, she went to the market'

(70) su: ne ya kawo wa Binta

3PL FOC $3 \mathrm{~m}+\mathrm{rc}$ bring IOM Binta

'it was them that he brought to Binta'

(71) ya: kawo wa Binta fa su:

3m bring IOM Binta PRT 3PL+IND

'indeed, he brought them to Binta'

(72) ita ce ya kawo wa abinci

$3 \mathrm{f}+\mathrm{IND}$ FOC $3 \mathrm{~m}+\mathrm{rc}$ bring IOM food

'it was her that he brought food'

To summarize, there is evidence from the non-interruptability of pronoun-host sequences that pronouns from the preverbal paradigms and from both object paradigms are syntactically dependent. In the case of the direct object pronouns, it would seem plausible to assume that they are verbal clitics, and I will do so. I will also assume that the unit formed by the indirect object marker ma and the dependent possessive pronouns which mark indirect object is syntactically dependent on the verb . Lastly, following Tuller [1986], I will assume that the dependent pronominal

${ }^{19}$ The modal particle placement parallel to (72) is not grammatical:

(i) *ya: kawo wa fa ita abinci

I assume that the explanation for this is the same as that for the ungrammaticality of (64). 
element corresponding to subject is part of INFL, an independent inflectional element containing tense/aspect features as well as the pronominal subject argument features. Representing the pronominal elements now as ARG, for argument, I am assuming a structure like that in (73), ignoring for the moment nominal subject position.

\section{(73) $\left[\mathrm{I}^{\prime}[\mathrm{INFL}\right.$ TENSE/ASPECT, ARG] [V'[V V, (ARG)] ... da NP] ] ]}

INFL and V can each take only one dependent ARG. ARG is optional in V, allowing thereby intransitive as well as transitive verbs. When an indirect object is present and adjacent to the verb, the direct object pronoun is from the independent paradigm and is not a dependent argument.

4.2. The structural configuration of asymmetric coordination. In Schwartz [1987b] I argue that cross-linguistically, the linking morphemes in asymmetric coordinations, such as Hausa da, are preposition-like in that they are case-assigners which function to sanction the presence of an NP in the syntactic structure but that they are unlike true or semantic prepositions in that they do not assign a thematic role to their objects. Rather, the thematic role of their objects must be determined by the thematic roles associated with the verb, the nature of the NP object, and the pragmatics of the event. For example, da wuka 'with a knife' will most likely have an instrumental role because of the referent of the word wuka ' $k$ nife' and the presence of a verb which is compatible with a knife having an instrumental role in the event expressed by its clause; $d a$ safe 'in the morning' will most likely be interpreted as a temporal expression because of the nature of the word safe 'morning' and the compatibility of such an interpretation with the event expressed in the clause; $d a$ fushi 'angrily' will most likely be interpreted as a manner expression because of the nature of the word fushi 'anger' and the expression of a compatible event in the clause; da Binta 'with Binta' will most likely be interpreted as a comitative or as a member of an asymmetric coordination (or both interpetations will be possible) depending on the potential roles that the participant referred to by the name $B$ inta can play in the event expressed in the clause and on the presence or absence of a plural pronoun in the appropriate structural configuration.

It is now possible to identify the appropriate structural configuration for the interpretation of a da-phrase as a member of a thematic coordination corresponding to a given grammatical function. A preliminary version of the interpretive rule is given in (74).

(74) Given the configuration $[X[X \ldots A R G[P L]], \ldots$ da NP ], optionally absorb the features of NP into the feature set specified in ARG[PL]. 
The spirit of what (74) expresses is that a da-phrase can be semantically combined with, or incorporated into, a plural argument internal to the head of the phrase to which the da-phrase belongs. Since in the structure given in (73) there are potentially two dependent ARGs, both dependent on the heads of phrases to which the da-phrase belongs, this should entail that if both are present, i.e. if there is an object pronoun as well as the preverbal pronoun present in the clause, the da-phrase should be able to be incorporated into either of them. ${ }^{20}$ This is correct: when that configuration occurs, either interpretation is possible. Thus, sentences in which both the subject and object are ARGs, the dual thematic coordination interpetation may be with either, as shown in (75) and (76).
(75) sun
gan mù da Binta
3PL+PAST see 1 PL \& Binta
i. 'they saw me and Binta'
ii. 'he and Binta saw us'
(76) sun fada mana labari da Binta
$3 \mathrm{PL}+\mathrm{PAST}$ tell to+1PL story \& Binta
i. 'they told the story to me and Binta'
ii. 'he and Binta told the story to us'

Using the INFL Phrase analysis of the clause in Hausa, I will assume here that the independent subject pronouns of Hausa are in SPEC position of IP (sister to I'), as shown in (77). 21

$$
\left[\text { IP pro-IND }\left[\mathrm{I}^{\prime} \mathrm{INFL}[\mathrm{V}, \mathrm{V} \ldots]\right]\right]
$$

20 Note that this entailment is correct no matter whether the da-NP is in VP or not when it is absorbed into INFL. That is, this analysis is neutral between placing the da-NP which is part of a subject asymmetric coordination in adjunct position, as in (i), or within the VP, as in (ii).

$$
\left[\mathrm{I}^{\prime} \ldots[\mathrm{VP} \ldots . . . \mathrm{da} \mathrm{NP} \ldots]\right.
$$

$$
\left[\mathrm{I}^{\prime} \ldots[\mathrm{VP} \ldots \mathrm{da \textrm {NP }}] \ldots\right]
$$

${ }^{21}$ The independent pronouns functioning as subject can be demonstrated to not be in Focus position, since their presence doesn't automatically require the relative verb forms. It remains to be demonstrated that they are not necessarily in Topic position. The analysis presented here crucially depends on the assumption that the independent pronouns in these structures are subjects, and it would have to be changed if they were demonstrated not to be subjects. An alternative analysis, suggested to me by Russ Schuh and based on the Topic assumption, is that the sequence [da NP] cannot unify with a NP in a non-argument position. This would depend on a different definition of the notion "argument position" than that used in a standard GB analysis, since in my analysis dependent arguments would have to count as being in an "argument position", given that I am not assuming here an incorporation, i.e. movement, analysis as in Baker [1988]. 
Under this assumption, the statement in (74) also entails that asymmetric coordinations should not be incorporated directly into the independent pronouns in Hausa. This is because the independent pronouns do not satisfy the structural condition for incorporation: they are not dependent on the head of a projection of which da-NP is a member. This entailment is also correct. Consider (78). Here, the independent pronoun appears and the crucial dual interpretation is not possible. Rather, in such cases there is only a compositional interpretation, with at least three members in the set.

(78) mu: mun je kasuwa da shi:

1PL-IND 1PL go market \& $3 \mathrm{~m}$

'we and he went to the market/we went to the market with him'

Some confirmation for the interpretive rule proposed in (74) comes from the contrast between (78) and (79).

(79) mui $^{\prime}$ da shi: mun je kasuwa

1PL-IND \& 3-IND 1PL go market

i. 'he and I went to the market'

ii. 'we and he went to the market'

In (79), as opposed to (78), the right structural configuration obtains for feature absorption and therefore for the dual interpretation if it is assumed that mu: dashi: is analyzed as in (80), where the independent pronoun is the head of an N-projection including the da-phrase, thus allowing absorption.

\section{$\left[{ }_{N P}[N\right.$ ARG, X] da NP]}

The analysis of [pro-IND da NP] as an NP constituent is justified on the basis of distributional evidence: such sequences occur in NP positions, e.g. in subject position, as heads of relative clauses, etc. 22

However, structures like (79) (and corresponding structures with object pronouns) were not consistently permitted to have a dual interpretation by my Hausa consultants. 23 Both accepted the dual interpretation for some structures of this type

${ }^{22}$ They can also be referred to anaphorically, e.g. by relative pronouns. However, the anaphoric evidence cannot be used to justify syntactic constituent status in the analysis presented here, because anaphoric interpretation is assumed to be a semantic relation rather than a syntactic one. Recall that the rule of thematic absorption would provide the appropriate semantics for this relation. ${ }^{23}$ The lack of consistency in this case is striking in light of the very clear and consistent judgements given by both consultants on all other structures investigated. In fact, in all of the languages for 
but rejected it for others, even with verbs, tense/aspect and participants held constant. Dr. Ismail tended to accept the dual interpretation more than he rejected it, while Dr. Sani tended to reject it more than he accepted it. This variation deserves a fuller investigation, but I would tentatively suggest at this point that a plausible hypothesis to account for variation here may have to do with the fact that the plural pronoun in this structure is from the independent paradigm and is itself the head of the construction rather than a syntactic dependent of a functionally distinct head. It is thus not structurally identical to the other cases where the dual interpretation is consistently possible. It may be that the similarities and differences between the structure in (80) and the typical asymmetric coordination structures represented in (73) are a source of variation in judgement about whether the dual interpretation is possible for structures like (80).

The analysis presented here gives a single, unified account of the dual interpretation of asymmetric coordinations in Hausa by identifying a dependent plural argument into which a da-phrase can be incorporated semantically. This accounts for its behavior as a controller in functional control structures, under the assumption that control is a semantic relation. Since the da-phrase is not syntactically represented as part of a coordination, its syntactic distribution (that is, the distribution of an adjunct da-phrase) is also compatible with this analysis.

\section{Remaining Issues}

The analysis presented thus far raises two serious questions which need to be addressed. First, as stated, it accounts for why the da-phrase doesn't combine directly with the independent pronominal argument mu: in a sentence like (78), because mu: isn't an argument dependent on the head of a projection (in the sense of dependency used here) of which da-NP is a member, but it doesn't yet account for why a coreference relation betweeen mu: and the $d a-$ phrase cannot be established indirectly on the basis of the fact that in other cases, overt subjects are interpreted as being coreferential with the ARG which is in INFL, as shown in (81).

(81) Audu ya: je kasuwa
Audu 3m go market
'Audu went to the market'

That is, given the schema in (82), it doesn't account for why the NP of the da-phrase cannot be incorporated into $A R G_{i}$, which in turn is coindexed with or otherwise interpreted as corefential to pro-IND . $_{\text {. }}$

which I have investigated similar constructions, judgements in general are very clear and consistent. 


$$
\text { [IP } \text { pro-IND }{ }_{\mathrm{i}}\left[\mathrm{I}_{\mathrm{I}}\left[\mathrm{INFL}_{\mathrm{NFL}} \mathrm{ARG}_{\mathrm{i}}, \mathrm{X}\right] \ldots d a \mathrm{NP}\right] \text { ] }
$$

Second, it also does not yet account for the dual thematic coordination interpretation of a sentence like (83) and other corresponding examples with other grammatical relations, such as those in (26-30).

(83) [da Audu kam [I mun je kasuwa] ]

\& Audu TOP 1PL go market

'as for Audu, he and I went to the market'

(lit: with Audu, we went to the market)

Here, the condition given in (74) is not satisfied, because the da-phrase is not in the projection containing the relevant plural ARG, and yet the dual interpretation is possible. The two problems which have to be resolved, then, are why a dual interpretation is possible when the da-phrase is outside of its clause and why it is not possible when the da-phrase is in its clause but an overt subject pronoun is present.

5.1. Thematic absorption as unification. I turn now to the first problem, how to avoid the dual interpretation of a clause containing a da-phrase when that clause has an overt independent pronoun which shares its thematic and grammatical relation with the da-NP. To deal with this problem, an account of Subject-INFL cross-reference must be provided, as well as a more explicit account of what it means to say that the features of the NP in the da-phrase are absorbed into the features of a plural argument dependent on the head of a projection.

5.1.1. Pronoun features. Both of the phenomena to be investigated in this section refer to pronominal information, so the first step is to specify how I assume this information to be structured. I will assume that Hausa pronouns have the feature composition given in (84), illustrated with examples from the independent paradigm. 
(84) Hausa pronominal features

$$
\text { Singular Plural }
$$

\begin{tabular}{|c|c|c|c|c|}
\hline first person & 1 & $\overline{n i t}$ & $1 \wedge(\sim 1)^{*}$ & mu: \\
\hline second person & $\begin{array}{l}2, \text { MASC } \\
2, \text { FEM }\end{array}$ & $\begin{array}{l}\text { kai } \\
k e:\end{array}$ & $2 \wedge(\sim 1)^{*}$ & $k u:$ \\
\hline third person & $\begin{array}{l}\text { 3, MASC } \\
\text { 3, FEM }\end{array}$ & $\begin{array}{l}\text { shir } \\
\text { ita }\end{array}$ & $3 \wedge(\sim 1)^{*}$ & su: \\
\hline
\end{tabular}

As can be seen in (84), I assume that expressions which are first person plural signify sets of individuals one of whom is Speaker and one (or more) of whom are not. Likewise, I assume that expressions which are second person plural signify sets of individuals one of whom is Addressee and the other (or others) of whom is not Speaker (it is left open as to whether the other members of the set specified by second person plural are Addressees or not). Finally, I assume that expressions which are third person plural signify sets of individuals of which all members are neither Speaker nor Addressee.

5.1.2. Thematic absorption. In order for the NP of the da-phrase to combine with ARG and yield a dual interpretation, the absorption operation will replace the feature specification $\left[(\mathrm{m})^{*}\right]$ (where $\mathrm{n}=1,2$, or 3 and $\mathrm{m}=(\sim 1)^{*}$ or $\left.(3)^{*}\right)$ with the more specific features and feature values of the NP-represented here $\left[\mathrm{F}_{\mathrm{NP}}\right]$, as shown in (85)-yielding [n $\left.\wedge\left[\mathrm{F}_{\mathrm{NP}}\right]\right]$ as the semantic interpretation of ARG. In (14), repeated here as (86a), the product of the absorption operation is shown in (86b).

$$
\left[\left[\mathrm{n} \wedge(\mathrm{m})^{*}\right] \ldots d a\left[\mathrm{~F}_{\mathrm{NP}}\right]\right]=\left[\mathrm{n} \wedge\left[\mathrm{F}_{\mathrm{NP}}\right]\right]
$$

(86) a. mun je kasuwa da shi: 1 PL go market \& $3 \mathrm{~m}$ 'he and I went to the market'

b. $\left[\left[1 \wedge(\sim 1)^{*}\right] \ldots d a\left[\mathrm{~F}_{\text {Audu }}\right]\right]=\left[1 \wedge\left[\mathrm{F}_{\text {Audu }}\right]\right]$

The process which I have termed "absorption" is more formally characterized as "unification" in the sense of Shieber [1986]. Unification combines feature values 
from two sets and selects the most specific feature value for any feature shared by the sets (see Shieber [1986] and Pollard and Sag [1987] for a more formal characterization of unification). The operation of unification fails if the sets contain contradictory feature values. The feature values for any NP other than first person are an extension of the feature value "non-first person", allowing for a unification in which "non-first person" is replaced by the more specific feature values corresponding to the NP of the da-phrase. The operation of thematic absorption given in (74) can now be stated as in (87).

\section{Thematic absorption}

Given the configuration $\left[\mathrm{X}^{\prime}\left[\mathrm{X} \ldots \mathrm{ARG}\left[\mathrm{n} \wedge(\mathrm{m})^{*}\right] \ldots\right] \ldots\right.$ da NP $]$, unify the features of NP and ARG.

5.1.3. Subject-INFL agreement. I assume that it is feature value compatibility 24 which characterizes well-formed agreement, so that in a sentence like (88), INFL may be said to agree with the subject pronoun in that both carry the relevant agreement features, and these feature values are compatible.
mu: mun je Kano
'we went to Kano'
1PL 1PL go Kano

This can also be considered to be an operation of unification, which unifies the features of an independent subject NP and those of the pronominal features in INFL. The unification fails, and the agreement relation is not satisfied, if the independent subject NP and ARG in INFL contain contradictory feature values, e.g. if the subject were yarinya 'girl' which has the gender feature value FEMININE and INFL were ya: 'he' which has the gender feature value MASCULINE. SubjectINFL agreement can be stated as in (89).

\section{Subject-INFL agreement}

Given the configuration $\left[{ }_{\mathrm{IP}} \mathrm{NP}\left[\mathrm{I}^{\prime}\left[\mathrm{I} X,\left[\mathrm{~F}_{\mathrm{PRO}}\right] \ldots\right]\right.\right.$ ], unify $\mathrm{NP}$ and $\left[\mathrm{F}_{\mathrm{PRO}}\right]$.

Although thematic absorption of the da-phrase in asymmetric coordination and subject-INFL agreement are both operations which unify features of an NP and an ARG into a single set, they are not identical operations. Thematic absorption is optional, requires that ARG have the feature value schema $\left[n \wedge(m)^{*}\right]$, and is not limited to a single grammatical relation but rather can occur with any grammatical

${ }^{24}$ See Barlow [1988] for a discussion of why compatibility rather than matching of features is preferable. 
relation expressible as a dependent ARG, i.e. subject, direct object, indirect object. Subject-INFL agreement is obligatory, is not limited in the feature value for NUMBER, but can apply only to pronominal features in INFL. It remains now to ensure that both unifications cannot apply to a structure like (78), repeated here as (90).

(90) mu: mun je kasuwa da shi:

1PL-IND 1PL go market \& $3 \mathrm{~m}$

'we and he went to the market/we went to the market with him'

Given the operations as they are outlined above, they must be mutually exclusive because the pronominal features in INFL are functionally distinct in the two structures. I have assumed in the discussion so far that these pronominal features, as relevant to Thematic Absorption, function semantically as an argument of the predicate of the clause in which they appear (this was part of the definition of "dependent argument"). However, in the presence of an overt subject, I would claim that they do not have argument status; rather, there is evidence that in Hausa, like in Chichewa as analyzed in Bresnan and Mchombo [1987], object pronominal features consistently function as dependent arguments while subject pronominal features in INFL are dependent arguments when an independent subject NP is absent but agreement features when an independent subject is present. One piece of evidence to support this analysis is the asymmetry in the distribution of independent NPs between subject and object. Dependent object arguments never cooccur with coreferent independent NP objects in simple sentences, while independent subject NPs and subject pronominal features can always cooccur, as illustrated in (91) and (92). 25

(91)
a. ta: je kasuwa
3f go market
b. *Binta je kasuwa
Binta go market

'she went to the market'

c. Binta ta: je kasuwa
Binta $3 \mathrm{f}$ go market

'Binta went to the market'

${ }^{25}$ They need not cooccur in all aspects, however, as illustrated in (i) and (ii) [Abraham 1959:9].
$\begin{array}{ll}\text { (i) Musa yana } & \text { zuwa } \\ \text { Musa } 3 \mathrm{~m}+\mathrm{PROG} & \text { come }\end{array}$
'Musa is coming'
$\begin{array}{ll}\text { (ii) Musa na } & \text { zuwa } \\ \text { Musa PROG come }\end{array}$
'Musa is coming' 

(92) a. ya: gan tà
$3 \mathrm{~m}$ see $3 \mathrm{f}$
b. ya: ga Binta
$3 \mathrm{~m}$ see Binta
'he saw her'
c. *ya: gan tà Binta
'he saw Binta'

Thus, the reason why there is no dual interpretation in (90) is because Thematic Absorption cannot apply since the pronominal features in INFL are agreement features rather than a dependent argument, and Thematic Absorption as stated in (87) applies only to ARG.

The question of how comitatives marked by $d a$ fit into the picture remains to be answered. I won't address that issue here, but I'd like to state briefly the direction that I intend to take. I will assume that the conceptual link between asymmetric coordinations and comitatives in Hausa and crosslinguistically is that comitative constructions, as well as other uses of linking elements like Hausa da, link an adjunct argument to a clause, and the role of this adjunct argument is pragmatically determined, while $d a$ in its function in asymmetric coordination links an NP to an argument position of the predicate rather than to the clause.

5.2. Thematic linking of displaced NP's. I will now turn to an examination of the problem of why a dual interpetation is possible when the sequence [da-NP] is outside of its clause. Current syntactic frameworks all assume that displaced topic or focus constituents such as those in (83) and (26-30), i.e. NP's in non-argument positions, will be linked to an argument position in the argument structure of a clause. This is done so that each noun phrase have an associated thematic relation, the assumption being that thematic relations are determined by the argument structure of clauses, requiring that all NP's be somehow linked to argument positions. However, I will not assume here that any syntactic mechanism is necessary to achieve this purpose. Rather, I suggest that the interpretive rule in (93) will suffice.

(93) An NP marked by da in a non-argument position is interpreted as a member of any pragmatically compatible clause.

This is possibly too restrictive given the variable judgements regarding NP-internal da-phrases, but at present I will leave it in this form. Thus, a da-phrase in an extraction structure will be linked semantically/pragmatically to a compatible clause (a clause in which a thematic role is available for the argument of the daphrase). This condition may be satisfied in several ways: (i) da-NP may be analyzed by (87) as the da-NP relevant for unification when a head-dependent plural 
ARG is present in the "candidate' clause; or (ii) it may be pragmatically interpreted as an adjunct in any compatible "candidate" clause. An implication of this is that a da-NP in a non-argument position which is interpreted by (93) as a member of a clause with more than one dependent plural ARG should be ambiguous, as is the case for da-NP's within a clause with more than one dependent plural ARG (see (75) and (76)). This implication is correct, as shown in (94) and (95).

(94) da Binta ne suka gan mù

\& Binta FOC 3PL-rp see 1PL

i. 'he and BINTA saw us'

ii. 'they saw me and BINTA'

(95) da Binta kam sun gan mù

\& Binta TOP 3PL see 1PL

i. 'as for Binta $a_{i}$, he and she $e_{i}$ saw us'

ii. 'as for Binta $a_{i}$, they saw me and her,'

\section{Symmetric Coordination and Asymmetric Coordination}

We may now assume that $d a$ has a lexical specification incorporating the analysis proposed here. It is specified as being a unification operator under the condition that the head of a projection to which it is syntactically linked contain a plural ARG. The da-phrase thus shares in the thematic role of the plural ARG and functions as part of this argument in control structures such as reciprocal constructions and those with adjunct modifiers. It is also true, however, that in symmetric coordination, the da-phrase shares the thematic role of another NP in an argument position. The difference here is that the semantics of these constructions are compositional. I therefore propose that for these constructions, da is an operator of set union, not unification. In set union, the members specified in both sets are simply added together with no requirement of feature compatibility, so that, for example, in a phrase like that in (96a), the set union would be as in (96b).

(96) a. (da) ni: (...) da shi:

b. $\{\{1\} \wedge\{3\}\}$

Similarly, the set union of (97a) would be that in (97b), 
(97) a. mun ... da shi:

b. $\left\{\left\{1 \wedge\left(\sim 1^{*}\right)\right\} \wedge\{3\}\right\}$

which is the ordinary compositional plural interpretation which Hausa and English both share for these constructions. What I would like to suggest, then, is that all languages with symmetric NP constitutent coordination have NP linkers which are set union operators. 26 On the other hand, a subset of languages, like Hausa, Russian, Chilean Spanish, and others, have NP linkers which are set unification operators. In fact, in Hausa, a single morpheme da serves both purposes. ${ }^{27}$ It isn't surprising that a single morpheme should have the three functions of comitativity, set union, and set unification. Conceptually, all involve addition: comitativity adds an argument to a clause where no argument is otherwise required by the argument structure of the predicate (though the predicate must be able to accommodate the added argument in a pragmatic sense); symmetric coordination (set union) adds individuals together to form a set in an argument position; and asymmetric coordination (set unification) adds a further specification to the information structure of the set of participants occupying an argument position.

26This proposal is made independently in Bond [1988].

${ }^{27}$ However, in other languages like Russian and Chilean Spanish, these are distinct and correspond to 'and' and 'with' constructions, where 'and' is an operator of union while 'with' is an operator of unification (as well as comitativity). 


\section{REFERENCES}

Abraham, R.C. 1959. The Language of the Hausa People . London: University of London Press.

Aissen, Judith. 1988. "Extensions of brother-in-law agreement." In M. Barlow and C. Ferguson (eds.), Agreement in Natural Language, pp. 219-236. Stanford: CSLI.

Baker, Mark. 1988. Incorporation. Chicago: University of Chicago Press.

Barlow, Michael. 1988. "A situated theory of agreement." Ph.D. dissertation, Stanford University.

Bond, Clay. 1988. "Coordination as recursive set union." Indiana University ms.

Bresnan, Joan and Sam Mchombo. 1987. "Topic, pronoun and agreement in Chichewa." Language 3:805-856.

Junaidu, Ismail. 1987. "Topicalization in Hausa." Ph.D. dissertation, Indiana University.

Kraft, Charles. 1970. "Hausa sai and dà-a couple of overworked particles." Journal of African Languages 9:92-109.

McCloskey, James. 1986. "Inflection and conjunction in Modern Irish." Natural Language and Linguistic Theory 4:245-281.

McCloskey, James and Kenneth Hale. 1984. "On the syntax of person-number inflection in Modern Irish." Natural Language and Linguistic Theory 1:487533.

Newman, Paul. 1979. "The historical development of medial /ee/ and /oo/ in Hausa." Journal of African Languages and Linguistics 1:173-188.

Newman, Paul. 1982. "Grammatical restructuring in Hausa: indirect objects and possessives." Journal of African Languages and Linguistics 4:59-73.

Newman, Paul. 1983. "The efferential (alias 'causative') in Hausa." In E. Wolff and R. Meyer-Bahlburg (eds.), Studies in Chadic and Afroasiatic Linguistics, pp. 397-418. Hamburg: H. Buske Verlag. 
Pollard, Carl and Ivan Sag. 1987. Information-based Syntax and Semantics, vol. 1. Stanford: CSLI.

Rizzi, Luigi. 1982. Issues in Italian Syntax. Dordrecht: Foris.

Sani, Sammani. 1987. "Sentential and predicate negation in Hausa." ms.

Schwartz, Linda. 1987a. "Constituent structure and grammatical relations." Paper presented at the Third Biennial Conference on Relational Grammar.

Schwartz, Linda. 1987b. "Coordination and comitative." Paper given at the UWM Symposium on Linguistic Categorization.

Schwartz, Linda. 1988a. "Asymmetric feature distribution in pronominal 'coordinations'." In M. Barlow and C. Ferguson (eds.), Agreement in Natural Language, pp. 237-250. Stanford: CSLI.

Schwartz, Linda. 1988b. "Conditions on verb-coded coordinations." In M. Hammond et al.(eds.), Studies in Syntactic Typology, pp. 53-73. Amsterdam: John Benjamins.

Schwartz, Linda. 1989. "Asymmetrical syntax and symmetrical morphology in African languages." In P. Newman and R. Botne (eds.), Current Approaches to African Linguistics, vol. 5, pp. 21-33. Dordrecht: Foris Publications.

Schwartz, Linda. In preparation. "A typology of asymmetric coordination."

Shieber, Stuart. 1986. An Introduction to Unification-Based Approaches to Grammar. Stanford: CSLI.

Tuller, Laurice. 1984. "Dative in Hausa." In C. Jones and P. Sells (eds.), Proceedings of NELS 14. Amherst, MA: University of Massachusetts.

Tuller, Laurice. 1986. "Bijective relations in Universal Grammar and the syntax of Hausa." Ph.D. dissertation, UCLA. 